\title{
Experimental studies on seed production of tropical grasses in Kenya. 3. The effect of nitrogen and row width on seed crops of Setaria sphacelata cv. Nandi II
}

\author{
J. G. Boonman \\ National Agricultural Research Station, Kitale, Kenya
}

Received: 15 August 1971

\section{Summary}

The effects of nitrogen levels ranging from 0 to $260 \mathrm{~kg} \mathrm{ha}^{-1} \mathrm{crop}^{-1}$ and row widths varying from broadcast sowing to $100 \mathrm{~cm}$ were studied in two experiments over five years. By applying $100 \mathrm{~kg} \mathrm{~N}$, yields of Pure Germinating Seed (PGS) and herbage dry matter were increased seven- and three-fold, respectively. The top nitrogen levels tended to decrease percentage and yield of PGS, especially at wide row width.

At $130 \mathrm{~kg} \mathrm{~N}$, rows $30 \mathrm{~cm}$ wide produced $33 \%$ higher yield of PGS than $90-\mathrm{cm}$ rows. This resulted largely from an increase in percentage PGS, apparently brought about by more concentrated heading and flowering in general at close row width. Percentage and yield of PGS varied tremendously from season to season, although dry matter yields and head numbers varied little. The highest yield of PGS was $48 \mathrm{~kg} \mathrm{ha}^{-1} \mathrm{crop}^{-1}$. It is suggested that of the various important yield components, seed setting is the one which varied most.

Rapid heading was preceded by rapid increase and subsequently rapid decline in tiller numbers.

Herbage dry matter yields were on average increased by 6.5 tons through an application of $100 \mathrm{~kg} \mathrm{~N}$, i.e. $65 \mathrm{~kg}$ dry matter per $\mathrm{kg} \mathrm{N}$.

\section{Introduction}

In the preceding papers (Boonman, 1971a, 1971b) it was shown that head emergence and flowering within heads are prolonged processes in tropical grasses limiting the yield and viability of harvestable seed. In widely spaced seed crops of Nandi head numbers at optimal harvesting stage rarely exceed 200 per $\mathrm{m}^{2}$ of which only part is effective. $B \in y o n d$ this optimal stage numbers were found to go up to 350 which exceeds the number commonly found in cocksfoot, a temperate grass with fair seed yields (Evans, 1959). Total head production may well be adequate in Nandi but achieving a more concentrated head emergence appears a prerequisite in attempting to increase seed yield.

The present study was undertaken to test the hypothesis that more even heading and maturation occur under conditions of close tiller density and appropriate nitrogen fertilization (Boonman, 1967). Tiller density ought to be such as to allow a high number 
of heads to emerge in a short time while suppressing the development and heading of late tillers. It was thought that the row width of $90 \mathrm{~cm}$ which was commonly used at that time was too wide to accomplish this.

The work reported below concerns two experiments carried out over five years and covering a range of row widths (R) from broadcast sowing to $100 \mathrm{~cm}$. The accompanying nitrogen (N) levels varied from 0 to $260 \mathrm{~kg} \mathrm{ha}^{-1} \mathrm{crop}^{-1}$.

The principal crop aspect studied was yield of Pure Germinating Seed (PGS). Determination of percentage PGS is important since it can vary greatly between seasons and years. It had also been observed that the yield of clean seed and the percentage PGS were differently affected by the treatments applied, especially by $\mathrm{N} .100 \mathrm{~kg} \mathrm{~N}$ per ha increased the yield of clean seed in Nandi but decreased the percentage PGS (Boonman, 1968).

In view of the above considerations attempts were made to follow the tillering and heading characteristics. Attention was also directed towards analysis of seed yield components, i.e. head number, grain weight and head length, the last as a measure of spikelet number per head (Gildenhuys, 1950). Total herbage dry matter yields at seed harvesting time were also recorded, as many seed growers regard the utilization of herbage left after seed harvesting as important.

Nandi is a popular variety in Kenya and elsewhere (Hacker and Jones, 1969). The cultivar Nandi II was chosen for this study because of its greater uniformity, although it yields considerably less seed than Nandi I (Boonman, unpublished data).

\section{Materials and methods}

Exp. I was planted on 7 April 1967 and Exp. II on 8 April 1968, both at the National Agricultural Research Station in Kitale. Exp. I was in four replicates of a $3^{2}$ lay-out three row widths, 30,60 and $90 \mathrm{~cm}$, each at three nitrogen levels, 0,130 and $260 \mathrm{~kg} \mathrm{~N}$ ha $^{-1}$ crop $^{-1}$. The crop in the 1 st year, 1967, did not receive $N$. In 1970 , the 0 -level of $N$ was changed to $65 \mathrm{~kg}$. Seed was planted by hand at a constant rate per length of row, according to commercial practice, and was mixed prior to planting with single superphosphate at $50 \mathrm{~kg} \mathrm{P}_{2} \mathrm{O}_{5}$ per ha. Top dressing with $\mathrm{P}_{2} \mathrm{O}_{5}$ was carried out annually. Row length was $8.5 \mathrm{~m}$. Arrangement of plots and rows was such that plot width for harvesting was always $3.6 \mathrm{~m}$, adjacent plots sharing one mutual guard-row. The field was burned once in April 1971 at the onset of the rains.

Exp. II was laid out in a 'central composite design', four treatments each at five levels in 30 plots with 2 replicates (Cochran and Cox, 1957). In addition to $N$ and $R$, seed rate $\left(0.2-1.8 \mathrm{~kg}\right.$ PGS per ha) and phosphate $\left(0-80 \mathrm{~kg} \mathrm{P}_{2} \mathrm{O}_{5}\right.$ per ha as single superphosphate) were studied at five equidistant levels. In the first crop after sowing, phosphate had no effect and seed rates above $1 \mathrm{~kg}$ PGS per ha reduced yield of PGS but not significantly (data not presented). Phosphate treatments were therefore discontinued and a flat rate of single superphosphate was applied annually. Hence $\mathrm{N}$ and $\mathrm{R}$ remained as sources of variation after the first crop. Table 4 shows the levels of $N$ and $R$ used. The combination $\mathrm{N}_{100} \mathrm{R}_{50}$, assumed to be the optimum, was adopted as the central point'. Rows were $10 \mathrm{~m}$ long and plot width for harvesting $3 \mathrm{~m}$. Two guard-rows separated adjacent plots. The crop in the first year, 1968, did not receive N.

In both experiments, hand weeding was carried out only in the first year. Harvesting time was decided upon according to experience. At harvest, the whole crop was cut back with sickles, weighed and sampled for dry matter yield, bound in sheaves and stooked. 
Table 1. Official rainfall figures (mm) for Kitale.

\begin{tabular}{|c|c|c|c|c|c|c|c|c|c|c|c|c|c|}
\hline \multirow[t]{2}{*}{ Year } & \multicolumn{13}{|c|}{ Month } \\
\hline & 1 & 2 & 3 & 4 & 5 & 6 & 7 & 8 & 9 & 10 & 11 & 12 & Total \\
\hline 1967 & 3 & 21 & 104 & 224 & 258 & 144 & 190 & 114 & 58 & 230 & 84 & 6 & 1436 \\
\hline 1968 & 1 & 147 & 69 & 201 & 95 & 127 & 176 & 121 & 60 & 88 & 57 & 18 & 1160 \\
\hline 1969 & 62 & 58 & 107 & 54 & 215 & 49 & 101 & 176 & 116 & 119 & 52 & 6 & 1115 \\
\hline 1970 & 106 & 9 & 226 & 144 & 136 & 89 & 177 & 205 & 86 & 83 & 32 & 14 & 1307 \\
\hline 1971 & 9 & 1 & 21 & 148 & 118 & 218 & 181 & 167 & 75 & 171 & 60 & 56 & 1225 \\
\hline \multicolumn{14}{|c|}{ Long-term } \\
\hline
\end{tabular}

Seed was beaten out two weeks later and dried in the sun or in an oven at a temperature not exceeding $40^{\circ} \mathrm{C}$. Seed was cleaned on a mechanical blower, stored for some months and tested for percentage PGS. Harvested herbage was not returned to the plot. Top dressing with $\mathrm{N}$ was carried out in March/April at the onset of the rains, and in June/July after the first crop had been cut.

At harvesting time, samples for tillering and heading characteristics were obtained by cutting $25 \mathrm{~cm}$ row length in each row in a line diagonally across the plot. On various occasions heads and tillers were counted as the crop developed. For methods and definitions used see Boonman (1971b).

The rainfall data are presented in Table 1.

\section{Results}

So far, 14 harvests have been taken, eight from Exp. I since 1967 and six from Exp. II since 1968.

At each harvest observations were carried out on tiller and head numbers, percentage reading tillers, head length, culm length, yields of dry matter and clean seed, yield and percentage of PGS and 1000-grain weight. Date of Initial Head Emergence (IHE, 5-10 heads per $\mathrm{m}^{2}$ ) was recorded in eight harvests. In 1968, 1969 and 1970, observations were conducted on tillering and heading at stages between cleaning cut and harvesting in a total of five crops. From 1969 onwards, stubble width was measured after each harvest to determine percentage 'stubble cover'.

The data thus accumulated, though too voluminous to present in full, provide an opportunity to report on the consistency of the results presented. Yields and percentages of PGS are listed in Table 2,3 and 4. The relevant formula is: yield of clean seed $X$ percentage PGS $=$ yield of PGS. Yields of dry matter are shown in Table 5 of Exp. II only. An analysis of seed yield components, tillering and heading is presented for the July 1969 harvest of Exp. I only as this was studied in most detail (Fig. 1 and 2, Table 6 and 7). The crop failures that occurred in 1968 with yields less than $5 \mathrm{~kg}$ PGS are not reported separately but they are included in the averages of Table 3.

Percentages are duly given as weighted means, although this precluded statistical analysis. Yields and $\mathrm{N}$ rates are given in $\mathrm{kg} \mathrm{ha}^{-1} \mathrm{crop}^{-1}$. 


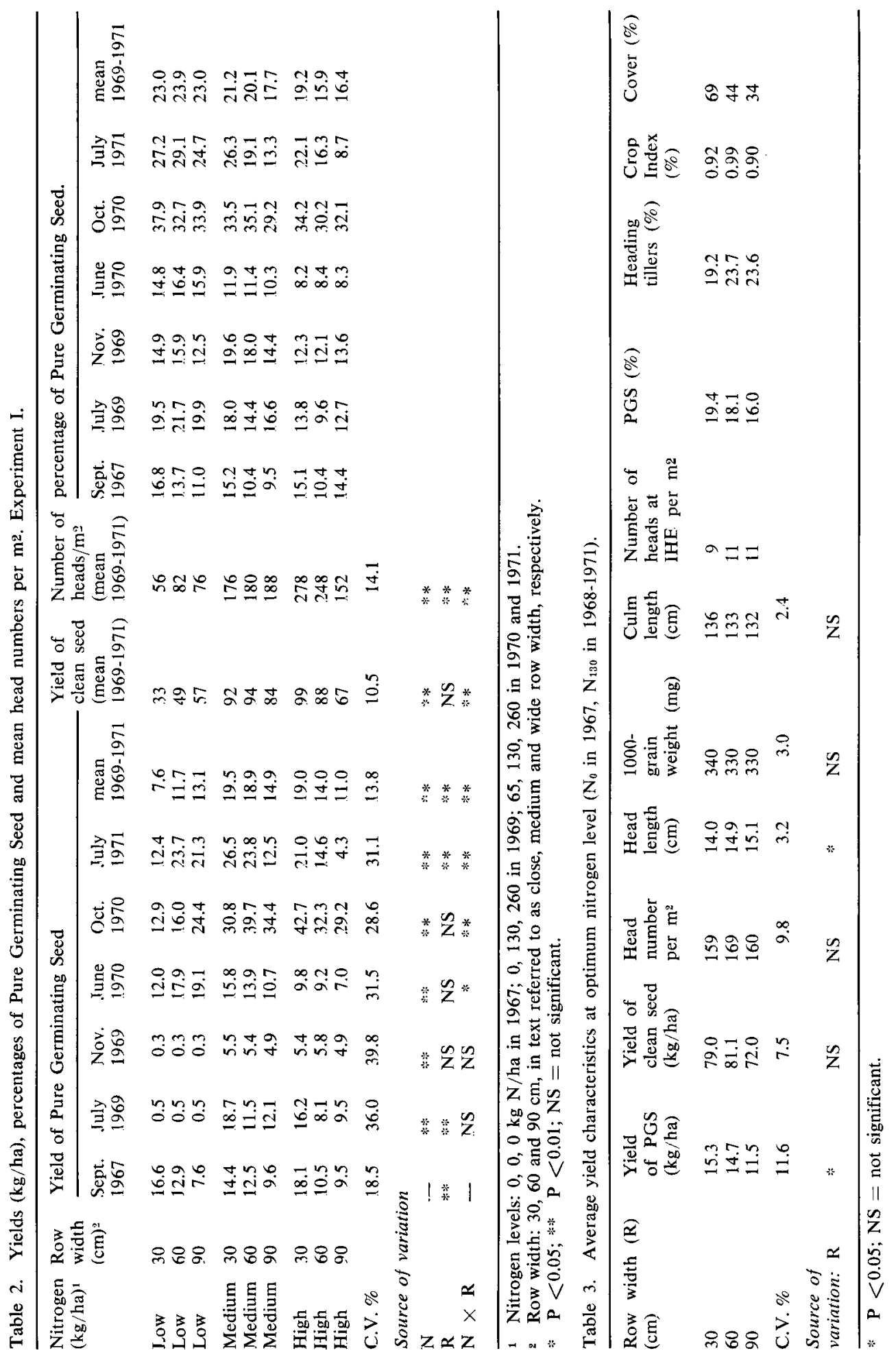




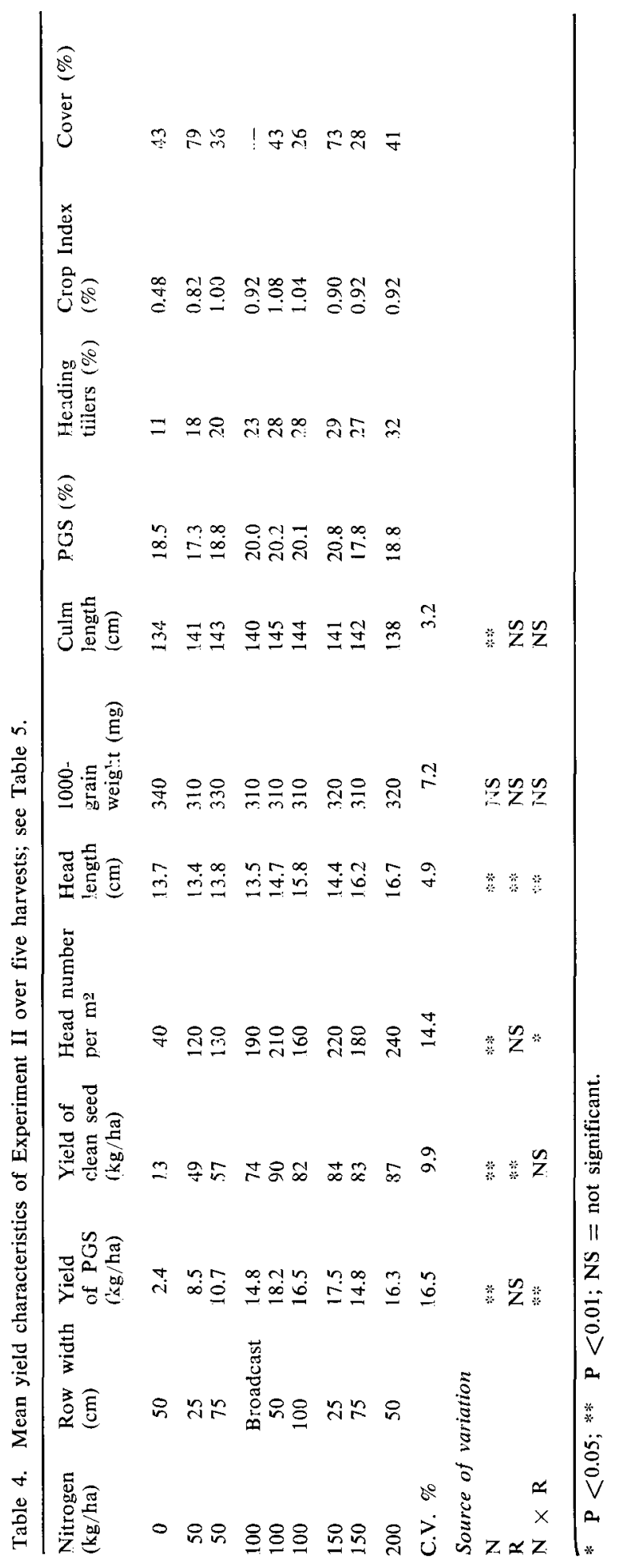




\section{The yield and percentage of PGS}

The superiority of adequate $N$ and close $R$ over the traditional $N_{65}$ and $R_{90}$ is borne out iil Table 2, 3 and 4.

In the absence of $\mathrm{N}$, yield of PGS dropped to an average of less than $2.5 \mathrm{~kg}$. A sevenfold increase resulted from an additional $100 \mathrm{~kg} \mathrm{~N}$. Between $\mathrm{N}_{50}$ and $\mathrm{N}_{150}$ yields more than doubled at $R_{25}$ (Table 4).

A strong $\mathbf{N} \times \mathbf{R}$ interaction prevailed. Close $\mathbf{R}$ outyielded wide $\mathbf{R}$ at medium and high $\mathrm{N}$ but not at low $\mathrm{N}$. Conversely, a pronounced response to $\mathrm{N}$ was confined to close $R$, the response to high $N$ being small or even negative at wide $R$ (Table 2 and 4). Apparently narrower $R$ required more $N$ to achieve high yield. Thus $N_{100} R_{50}$ yielded more than $\mathbf{N}_{150} R_{25}$ (Table 4). This interaction also explains why maximum yields were produced at $\mathbf{N}_{130} R_{30}$ in Exp. I and at $N_{100} R_{50}$ in Exp. II, as well as indicating why broadcast sowing yielded less than $R_{50}$ at $N_{100}$.

In only one harvest, October 1970, did the top $\mathrm{N}$-levels outyield medium $\mathrm{N}$. It was also affected by $\mathbf{N}$ and $R$. In Exp. $I$ it dropped with increase in $N$, particularly at wider is an indication in the data that the optimum $\mathrm{N}$-level was higher in crops with high yield levels.

Having established the medium $\mathrm{N}$-level as the most appropriate, it is now feasible to assess the effect of $R$ at this level (Table 3). By narrowing $R$ from 90 to 60 or 30 $\mathrm{cm}$, yield of PGS was increased by 29 and $33 \%$, respectively. The percentage PGS was also affected by $\mathbf{N}$ and $\mathbf{R}$. In Exp. $I$ is dropped with increase in $N$, particularly at wider R. Close $\mathbf{R}$ consistently produced a higher percentage PGS than wide $\mathbf{R}$ (Table 2). Table 3 shows that $\mathbf{R}_{30}$ produced $19.4 \%$ PGS against $16.0 \%$ at $\mathbf{R}_{90}$. This and the $10 \%$ increase in yield of clean seed from close $R$ accounted largely for the $33 \%$ increase in yield of PGS. However, head number, head length and percentage of heading tillers were all actually lowest at $\mathbf{R}_{\mathbf{3 0}}$. In Exp. II, $\mathrm{N}_{\mathbf{1 0 0}}$ produced a higher percentage PGS than

Table 5. Yields of dry matter (tons/ha). Experiment II.

\begin{tabular}{|c|c|c|c|c|c|c|c|}
\hline $\begin{array}{l}\text { Nitrogen } \\
\text { (kg/ha) }\end{array}$ & $\begin{array}{l}\text { Row width } \\
\text { (cm) }\end{array}$ & $\begin{array}{l}\text { July } \\
1969\end{array}$ & $\begin{array}{l}\text { Nov. } \\
1969\end{array}$ & $\begin{array}{l}\text { June } \\
1970\end{array}$ & $\begin{array}{l}\text { Oct. } \\
1970\end{array}$ & $\begin{array}{l}\text { July } \\
1971\end{array}$ & Mean \\
\hline 0 & 50 & 3.1 & 1.9 & 1.9 & 2.6 & 2.8 & 2.5 \\
\hline $\begin{array}{l}50 \\
50\end{array}$ & $\begin{array}{l}25 \\
75\end{array}$ & $\begin{array}{l}7.6 \\
7.7\end{array}$ & $\begin{array}{l}5.3 \\
5.5\end{array}$ & $\begin{array}{l}6.2 \\
5.7\end{array}$ & $\begin{array}{l}5.7 \\
5.7\end{array}$ & $\begin{array}{l}5.6 \\
5.1\end{array}$ & $\begin{array}{l}6.1 \\
5.9\end{array}$ \\
\hline $\begin{array}{l}100 \\
100 \\
100\end{array}$ & $\begin{array}{l}\text { Broadcast } \\
50 \\
100\end{array}$ & $\begin{array}{l}8.6 \\
9.1 \\
8.9\end{array}$ & $\begin{array}{l}7.9 \\
8.9 \\
8.8\end{array}$ & $\begin{array}{l}8.5 \\
9.6 \\
8.5\end{array}$ & $\begin{array}{l}9.4 \\
8.9 \\
8.6\end{array}$ & $\begin{array}{l}7.9 \\
8.7 \\
7.5\end{array}$ & $\begin{array}{l}8.5 \\
9.0 \\
8.5\end{array}$ \\
\hline $\begin{array}{l}150 \\
150\end{array}$ & $\begin{array}{l}25 \\
75\end{array}$ & $\begin{array}{l}9.1 \\
9.1\end{array}$ & $\begin{array}{r}10.0 \\
9.8\end{array}$ & $\begin{array}{r}10.8 \\
9.9\end{array}$ & $\begin{array}{l}9.1 \\
9.4\end{array}$ & $\begin{array}{l}10.9 \\
10.1\end{array}$ & $\begin{array}{r}10.0 \\
9.7\end{array}$ \\
\hline 200 & 50 & 9.6 & 10.8 & 10.8 & 11.1 & 9.2 & 10.3 \\
\hline C.V. \% & & 12.5 & 10.3 & 14.6 & 14.1 & 15.0 & 8.0 \\
\hline \multicolumn{8}{|c|}{ Source of variation } \\
\hline $\mathbf{N}$ & & $* *$ & 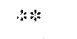 & $* *$ & $* *$ & $* *$ & $* ;$ \\
\hline$\stackrel{\mathbf{R}}{\mathbf{N} \times \mathbf{R}}$ & & $\begin{array}{l}\text { NS } \\
\text { NS }\end{array}$ & $\begin{array}{l}\text { NS } \\
\text { NS }\end{array}$ & $\begin{array}{l}\text { NS } \\
\text { NS }\end{array}$ & $\begin{array}{l}\text { NS } \\
\text { NS }\end{array}$ & $\begin{array}{l}\text { NS } \\
\text { NS }\end{array}$ & $\begin{array}{l}\text { NS } \\
\text { NS }\end{array}$ \\
\hline
\end{tabular}

** $\quad P<0.01 ; \mathrm{NS}=$ not significant. 
Maximum number of tillers per $\mathrm{m}^{2}$

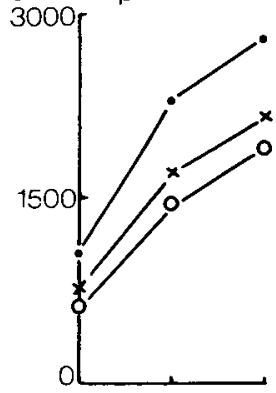

Yield of clean seed in $\mathrm{kg} / \mathrm{ha}$
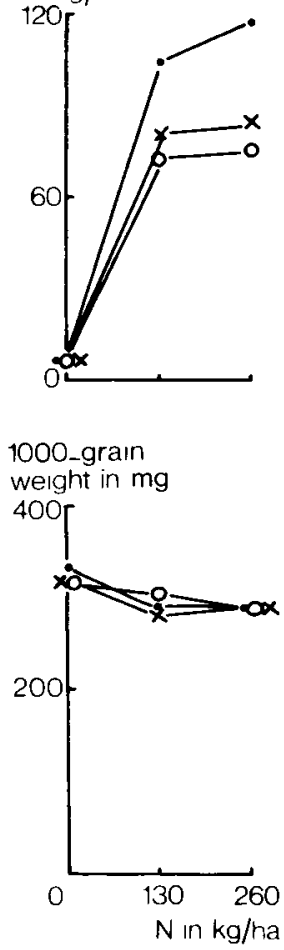

Number of heading tillers per $\mathrm{m}^{2}$

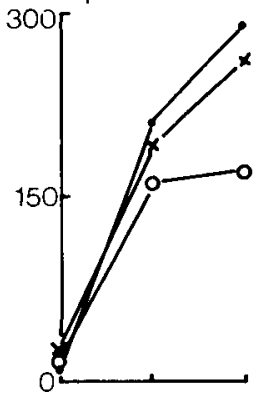

Crop Index

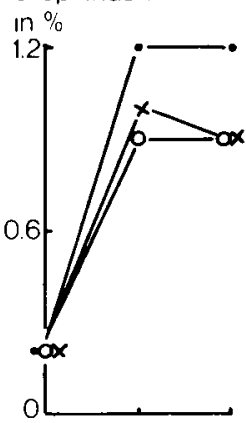

Head length in $\mathrm{cm}$

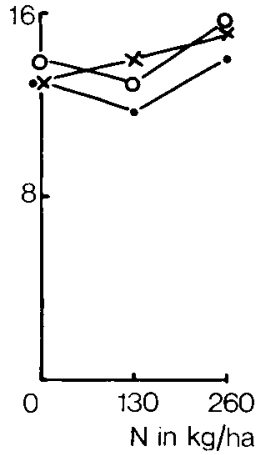

Headıng tillers

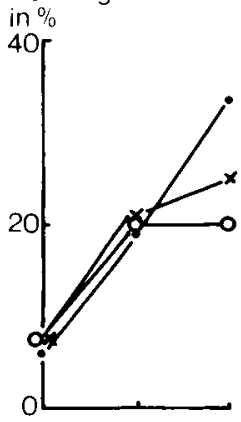

Yield of PGS

in $\mathrm{kg} / \mathrm{ha}$

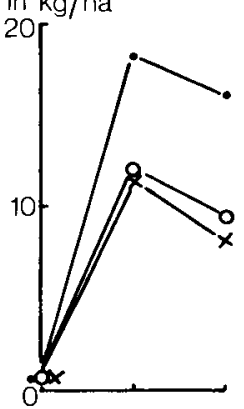

Culm length

in $\mathrm{cm}$

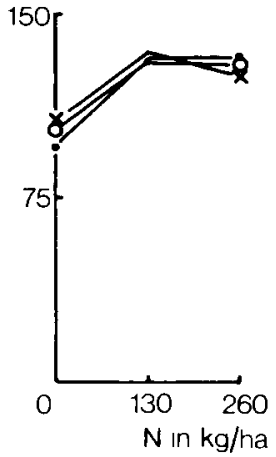

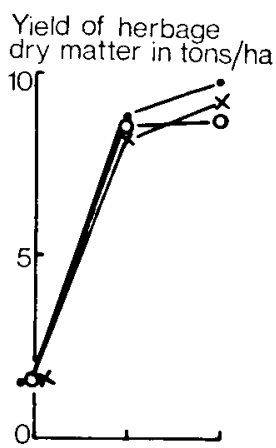

PGS

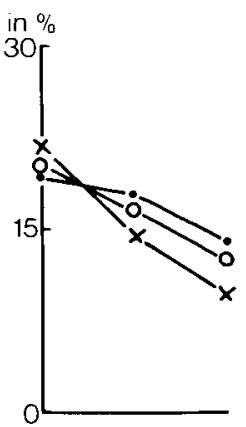

Number of heads per $\mathrm{m}^{2}$ at IHE

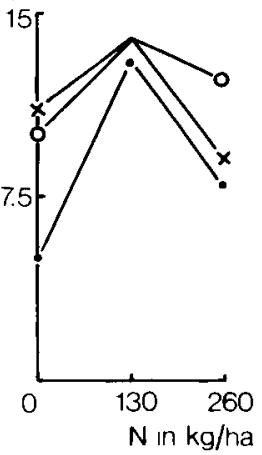

Fig. 1. Crop characteristics, July 1969, Experiment I. Row widths: $\mathrm{o}-\mathrm{o} 90 \mathrm{~cm}$.

the lower $\mathrm{N}$-levels, and although the highest percentage was found at $\mathrm{N}_{150} \mathbf{R}_{25}$, a higher yield of PGS was actually obtained at $N_{100} R_{50}$ due to a proportionally higher yield of clean seed. Head numbers, head length, percentage heading tillers and 1000-grain weight were similar in both treatment combinations. It is further borne out in Table 2 
that although mean head numbers were highest at $\mathrm{N}_{\mathbf{2 6 0}}$, except in wide rows, percentage and yield of PGS were lower than at $\mathbf{N}_{\mathbf{1 3 0}}$. It is therefore apparent that head numbers, when increased through high $\mathrm{N}$, did not result in increased yield of PGS (see also Fig. 1).

A most striking feature of both experiments is the great variation in yield and percentage of PGS between seasons, as is evident in Table 2.

\section{Yield of herbage dry matter}

The highest yields of dry matter at seed harvesting time were produced at the top $\mathrm{N}$ levels (Table 5). Top yields exceeded 10 tons per crop. In the absence of $\mathrm{N}$, yields were often less than 2.5 ton per ha. By applying $100 \mathrm{~kg} \mathrm{~N}$ yields were increased on average by 6.5 tons, i.e. a return of $65 \mathrm{~kg}$ dry matter per $\mathrm{kg}$ applied $\mathrm{N}$. There was a tendency in Exp. I of yields being higher at close R, but only at high N-level (see Fig. 1).

In contrast to seed yields, dry matter yields varied little from season to season.

\section{Seed yield components, tillering and heading; crop of July 1969. Experiment I.}

Fig. 1 shows graphs of various crop aspects. Apart from head numbers at IHE and tiller numbers when at their maximum, all observations refer to harvesting time.

$\mathrm{N}$ increased maximum tiller numbers, head numbers, percentage heading tillers, yields of dry matter, clean seed and PGS, Crop Index and culm length, the effects being quadratic in all cases (Fig. 1). $\mathrm{N}$ decreased percentage PGS and 1000-grain weight.

Most crop aspects were affected by the $N \times R$ interaction. At $\mathbf{N}_{260}$, close $R$ was superior in increasing percentage heading tillers, head number, yield of dry matter and clean seed, yield and percentage of PGS and Crop Index. Close R reduced head length. At $\mathrm{N}_{130}$, differences between row widths were less marked, while at $\mathrm{N}_{0}$ the effects were often reversed. Conversely, the effect of $\mathrm{N}$ was more pronounced at $R_{30}$ than at $R_{90}$. As shown in Tables 3 and 4, percentage of heading tillers in close $\mathrm{R}$ was lower at medium $\mathrm{N}$, but higher at high $\mathrm{N}$.

It is also evident that although percentage heading tillers, head number and yield of clean seed were highest at $\mathrm{N}_{260}$, this did not apply to yield of PGS due to a reduction in percentage PGS. This is in line with what was observed earlier in Tables 2 and 4 and it is of interest to note the general agreement between the particular crop aspects of July 1969 and those in other harvests.

The data on Crop Index indicate that seed yield suffered more from lack of $\mathrm{N}$ than did the yield of dry matter. (See also Table 4.)

In Fig. 2 numbers and weights of tillers are shown only since patterns of increase and decline in numbers of non-heading tillers were similar to those shown in Fig. 1 of the previous paper (Boonman, 1971b). It suffices to state that the weight of non-heading tillers was overtaken by weight of heading tillers at seed harvesting time in one treatment only, $\mathrm{N}_{\mathbf{2 6 0}} \mathrm{R}_{\mathbf{3 0}}$. Numbers of heading tillers remained below numbers of nonheading tillers throughout. The presentation is further simplified by the omission of the data for $R_{60}$ which consistently fell between $R_{30}$ and $R_{90}$.

The increase in tiller numbers and weights was most rapid in $R_{30}$ at both $N_{260}$ and $\mathrm{N}_{130}$, followed by $\mathrm{N}_{260} \mathrm{R}_{90}$ (Fig. 2). This is also evident from the graph on maximum tiller numbers in Fig. 1. Tiller numbers were even higher at $\mathbf{N}_{\mathbf{1 3 0}} \mathbf{R}_{\mathbf{3 0}}$ than at $\mathbf{N}_{\mathbf{2 6 0}} \mathbf{R}_{\mathbf{9 0}}$, 

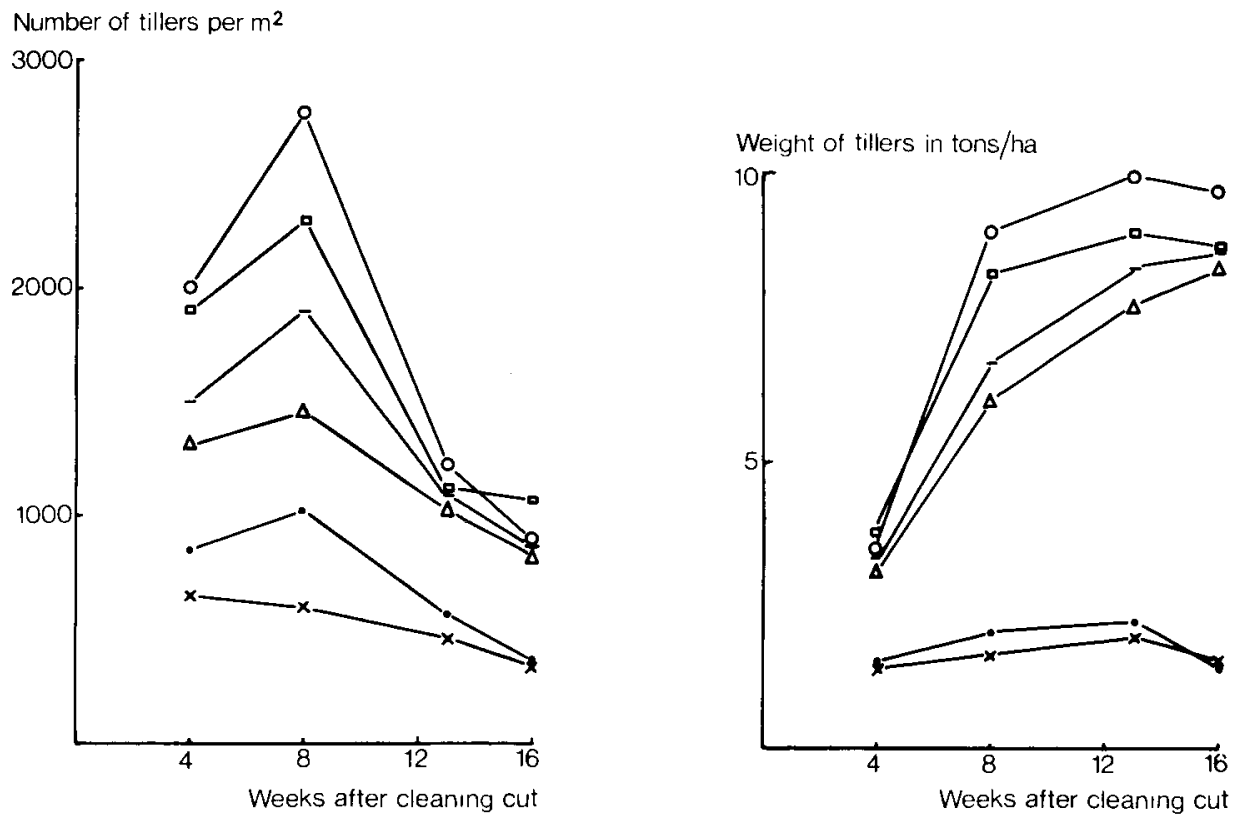

Fig. 2 .Tillering in Setaria sphacelata cv. Nandi II, seed crpo July 1969, at various nitrogen levels and row widths. $0 \longrightarrow \mathrm{N}_{\mathbf{2 6 0}} \mathbf{R}_{\mathbf{3 0}} ; \square-\square \quad \mathrm{N}_{\mathbf{1 3 0}} \mathbf{R}_{\mathbf{3 0}}$; . $\mathrm{N}_{0} \mathbf{R}_{30} ; \mathrm{x} \longrightarrow \mathrm{x} ; \mathrm{x} \longrightarrow \mathrm{x} \mathbf{N}_{0} \mathbf{R}_{\mathbf{0}}$.

and yet final numbers were similar at both row widths (Fig. 2). Hence decline in number was found to be most severe where the initial increase had been most rapid. For instance at $\mathrm{N}_{260} \mathrm{R}_{30}$ numbers of tillers dropped from a maximum of 2800 to 900 per m². Although numbers of tillers differed markedly at the first sampling date total weights differed only little, and consequently, weight per tiller was lowest at $\mathbf{N}_{\mathbf{2 6 0}} \mathbf{R}_{\mathbf{3 0}}$.

The numbers of heading tillers are shown in Table 6 . The increase was almost linear between IHE and harvesting time. As with maximum tiller numbers, numbers of heads were highest in $R_{30}$ at both $N_{260}$ and $N_{130}$, followed by $N_{260} R_{90}$ etc. in the same

Table 6. Head numbers per $\mathrm{m}^{2}$ in seed crop of July 1969 (Exp. I).

\begin{tabular}{|c|c|c|c|c|c|}
\hline \multirow{2}{*}{$\begin{array}{l}\text { Nitrogen } \\
(\mathrm{kg} / \mathrm{ha})\end{array}$} & \multirow{2}{*}{$\begin{array}{l}\text { Row width } \\
(\mathrm{cm})\end{array}$} & \multicolumn{4}{|c|}{ Weeks after cleaning cut } \\
\hline & & 8 & 10 (IHE) & 13 & 16 (seed harvest) \\
\hline 0 & 30 & 4 & 5 & 11 & 12 \\
\hline 0 & 90 & 6 & 10 & 14 & 13 \\
\hline 130 & 30 & 3 & 13 & 150 & 210 \\
\hline 130 & 90 & 5 & 14 & 110 & 160 \\
\hline 260 & 30 & 3 & 8 & 160 & 290 \\
\hline 260 & 90 & 5 & 12 & 90 & 170 \\
\hline
\end{tabular}


SEED PRODUCTION OF TROPICAL GRASSES IN KENYA. 3

Table 7. Head length in seed crop of July 1969 (cm); Exp. I.

\begin{tabular}{lll}
\hline $\begin{array}{l}\text { Weeks after } \\
\text { cleaning cut }\end{array}$ & $\begin{array}{l}\text { Overall } \\
\text { head length }\end{array}$ & $\begin{array}{l}\text { Length of } \\
\text { just-emerged } \\
\text { heads }\end{array}$ \\
10 (IHE) & 14.6 & 17.7 \\
13 & 14.8 & 13.3 \\
16 (seed harvest) & 13.8 & 12.9 \\
\hline
\end{tabular}

sequence as the maximum tiller numbers of Fig. 2. This shows clearly that $R$ was more efficient in accelerating head emergence than $N$. $R_{90}$ benefitted little from the increase in $\mathrm{N}$ from $\mathrm{N}_{\mathbf{1 3 0}}$ to $\mathrm{N}_{\mathbf{2 6 0}}$, in contrast to $\mathbf{R}_{\mathbf{3 0}}$.

That close $\mathrm{R}$ not only led to greater head numbers as such, but also to a greater number produced in a shorter length of time can be seen from the IHE graph of Fig. 1, which shows the IHE head numbers of Table 6 in more detail. Head numbers were significantly lower at $\mathbf{R}_{30}$. The same trend was observed in $70 \%$ of the crops studied for this aspect which revealed that head numbers at IHE were on average 8,10 and 11 per $\mathrm{m}^{2}$ at $\mathbf{R}_{\mathbf{3 0}}, \mathbf{R}_{60}$ and $\mathbf{R}_{90}$ respectively. Hence onset of heading is delayed at $\mathbf{R}_{30}$. It is also evident from Fig. 1 and Table 6 that IHE head numbers were highest at medium $N$. This trend was also confirmed in $75 \%$ of the crops. Both low and high $\mathrm{N}$ retarded the onset of heading.

An attempt was made to study variation in tiller length as a measure of stage of development. It was found that close $R$ was characterized by the occurrence of a much higher number of longer tillers than wide $R$ (data not presented).

Head length was increased by $\mathbf{N}$ and $\mathbf{R}$ (Fig. 1, Table 4). A comparison of overall head length and the length of just-emerged heads at differend stages of heading is shown in Table 7. The length of just-emerged heads decreased after the date of IHE, but exceeded overall head length on that date. Consequently, the first emerging heads were not the longest. This was also observed in the first crop after sowing.

In the first crop after sowing, the head lengths averaged $17-19 \mathrm{~cm}$, but such lengths were rare in subsequent crops, where the usual length was $13-16 \mathrm{~cm}$.

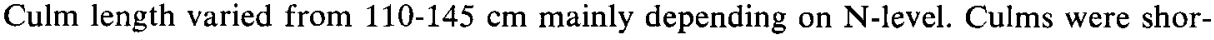
test in the absence of $\mathrm{N}$.

\section{Discussion}

The higher yielding ability of appropriate $\mathrm{N}$ and close $\mathrm{R}$ over the traditional $\mathrm{N}_{65}$ and $R_{90}$ is evident. There was a good agreement between the two experiments.

Yield of PGS increased seven-fold by raising $N_{0}$ to $N_{100}$ and two-fold from $N_{50}$ to $\mathrm{N}_{150}$, at $R_{25}$ (Table 4). Conversely, by narrowing $R_{90}$ to $R_{30}$ at $N_{130}$ yield of PGS was increased by one third.

A strong $\mathbf{N} \times \mathbf{R}$ interaction was prevalent. At close $R$ more $N$ was required to achieve high yield. On the other hand wide $R$ responded little to $N$. It appears as if a row width of $30-50 \mathrm{~cm}$ is optimal. At current prices $1 \mathrm{~kg}$ PGS pays for $20 \mathrm{~kg} \mathrm{~N}$.

The response to both high $\mathbf{N}$ and close $\mathbf{R}$ was most pronounced in harvests with high yield levels. Without $\mathrm{N}$ yields decreased rapidly after the first crop. It has also been 
observed that $\mathbf{N}$ is most efficient when applied as early as possible at the beginning of growth, since late $\mathrm{N}$ has little if any effect (Boonman, 1968).

A striking feature in both experiments was the huge season-to-season variation. Crops in 1968 did not even yield $5 \mathrm{~kg}$ PGS per ha. In contrast, the October 1970 harvests yielded a maximum of $48 \mathrm{~kg}$ in Exp. II and $43 \mathrm{~kg}$ in the fourth year running of Exp. I (Table 2 and 4). Dry matter yields were remarkably constant (Table 5). This, when considered along with the rainfall data (Table 1), does not suggest that conditions were poor for growth in general. However, low seed yields were obtained in seasons which received lower rainfall especially in the month around early heading, and vice versa. It also appeared that low rainfall during maturation was favourable for seed yield. This tendency needs to be confirmed over a wider range of years and yield records, but it does seem that seed yield is extremely sensitive to climatic variations, in contrast to herbage yields.

A response of $65 \mathrm{~kg}$ dry matter per $\mathrm{kg} \mathrm{N}$ applied was found at $\mathrm{N}_{100}$ (Table 5). Yields of clean seed were very low in contrast to the high yields of dry matter, and therefore a very low Crop Index was obtained, rarely above $1 \%$ (Fig. 1, Table 3 and 4). Seed yield was more sensitive to $\mathrm{N}$ than dry matter yield.

Comparing final seed yield and its components, low head numbers were invariably correlated with low seed yields (Table 2, 3 and 4, Fig. 1). Yield differences at high levels of head numbers were due to other components as well since increases in yield of PGS and head numbers were often not parallel. Of these components, 1000-grain weight was only slightly affected by treatments. As was seen in Table 3 yield of PGS was one third higher at $\mathbf{R}_{\mathbf{3 0}}$ than at $\mathbf{R}_{\mathbf{9} 0}$, but values for percentage heading tillers, head number and head length were actually lowest at $\mathbf{R}_{\mathbf{3 0}}$. The increase in PGS yield was accounted for by an increase in percentage PGS and yield of clean seed. Hence better seed setting more than compensated for the decreased head length and number of heads.

The importance of seed setting is also evident if the large season-to-season variation between harvests with equal head numbers is considered. For instance, with 260 heads per m $\mathrm{m}^{2} 8 \mathrm{~kg}$ PGS per ha were produced at $\mathrm{N}_{\mathbf{2 6 0}} \mathrm{R}_{60}$ in July 1969 , and no less than $48 \mathrm{~kg}$ at $N_{200} R_{50}$ in October 1970 , i.e. a six-fold variation. The real difference was due to the seed setting, which was 3 and $18 \mathrm{mg}$ PGS per head in the seasons mentioned.

It was pointed out by Langer and Lambert (1963) that yield components do not vary independently. This makes it hazardous to attach much value to correlations between yield and a single component of seed yield. For example, nitrogen increased percentage heading tillers, head number and head length, but high head numbers when increased by high $\mathrm{N}$ led to decreased percentage and yield PGS particularly at wide $\mathrm{R}$ (Table 2 and 4 ).

Although high $\mathrm{N}$ may have had a direct negative effect on seed setting, other factors may be involved. Lodging did not appear to be detrimental since high yields were often associated with bad lodging. High $\mathbf{N}$ may delay maturation but visual rating of seed retention in a random head sample produced no evidence to that effect. As far as the effect of $\mathrm{N}$ on 1000-grain weight is concerned, there was no further drop beyond medium $N$. The highest weight was achieved at $N_{0}$. $N$ increased head length, which may lead to prolonged flowering and reduced seed setting per head. Bean (1969) measured the correlation between seed fertility and inflorescence size in tall fescue and found a negative correlation. It is further important to note that the top $\mathrm{N}$-level reduced head numbers very markedly at wide $\mathrm{R}$ in Exp. (Table 2). High $\mathrm{N}$ had no negative effect in the highest yielding crop, October 1970 .

The effect of $\mathbf{R}$ on percentage PGS was more beneficial (Table 3). This can only 
have been brought about by more even seed maturation. It was shown in Fig. 1 and Table 6 that close $R$ not only produced higher numbers of heads but also a delayed onset of heading. This delay may well have amounted to half a week or more as head numbers increased very slowly before IHE. Hence more heads were produced in a shorter period of time at close $R$. The effect of this concentrated head emergence on seed maturation may be enhanced by the shorter head length found at close $R$. It is possible that flowering is more even in shorter heads (Boonman, 1971a) and that this may more than compensate for any decrease in the number of spikelets in shorter heads.

Heading and tillering patterns were closely associated. The more rapid the increase in head numbers, the more rapid was the increase and subsequent decline in tiller numbers (Fig. 2 and Table 6). Treatments affected maximum head numbers and maximum tiller numbers and weights in the same sequence. Close $\mathbf{R}$ and high $\mathbf{N}$ encouraged rapid tiller and head production, the former being far more effective. An even distribution of tillers seems a prerequisite. Measurements of stubble width indicated that percentage stubble cover was 34,44 and $69 \%$ when $R$ was 90,60 and $30 \mathrm{~cm}$, respectively (Table 3 ). The closer the row width the higher was the maximum tiller number. This may explain the greater demand for $\mathrm{N}$ in order to achieve high seed yield at close tiller density, and also the fact the broadcast sowing lagged behind wider $R$ at $N_{100}$ (Table 4). The steep drop from high maximum to almost similar tiller numbers at harvesting time appears wasteful (Fig. 2). Dying tillers may however serve a purpose in retaining and redistributing nutrients to support head development in earlier tillers, since tillers can be emptied and spent (Sonneveld, 1962). Incidentally, the lower percentage heading tillers observed at close $\mathrm{R}$ and medium $\mathrm{N}$ (Table 3 ) points to the existence of a larger reservoir of tillers. A more rapid drop in tiller number also signifies that formation-minus-death is less. Consequently it may be assumed that tiller formation ceases at an earlier date in the quickly closed tiller canopy of close R. The highest numbers found in these experiments were 2860 tillers and 380 heads, both at $\mathrm{N}_{\mathbf{2 6 0}} \mathrm{R}_{\mathbf{3 0}}$.

Ryle (1966) has pointed out that light and $\mathrm{N}$ increase head length. This may explain some of the effects of $\mathrm{N}$ and $\mathrm{R}$ on average head length but it is as yet unclear why the earliest formed heads were shorter than those emerging slightly later (Table 7). He also showed that seed setting efficiency decreased in late emerging heads of rye grass.

Close $\mathbf{R}$ also had practical advantages. A complete ecological control of weeds and volunteer seedlings was maintained in the absence of inter-row cultivation, in contrast with wide $\mathrm{R}$. A more even sward is produced which facilitates mechanical cutting and removal of herbage. Finally, close $R$ recovered more quickly after a burn at the onset of the rains.

As regards the phosphate and seed rate treatments that were applied at sowing phosphate had virtually no effect at all and seed rates above $1 \mathrm{~kg}$ PGS per ha reduced yield of PGS in the first crop after sowing, albeit not significantly (data not presented)

\section{References}

Bean, E. W., 1969. Environmental and genetic effects upon reproductive growth in tall fescue (Festuca arundinacea Schreb.). J. agric. Sci. Camb. 72: 341-350.

Boonman, J. G., 1967. A. Rep. natn. agric. Res. Stn Kitale.

Boonman, J. G., 1968. A. Rep. natn. agric. Res. Stn Kitale.

Boonman, J. G., 1971a. Experimental studies on seed production of tropical grasses in Kenya. 1. General introduction and analysis of problems. Neth. J. agric Sci. 19: 23-36.

Boonman, J. G., 1971b. Experimental studies on seed production of tropical grasses in Kenya. 2. Tillering and heading in seed crops of eight grasses. Neth. J. agric. Sci. 19: 237-249. 
Cochran, W. G. \& G. M. Cox, 1957. Experimental designs. Wiley, New York.

Evans, G., 1959. Seed rates of grasses for seed production. I. Pasture varieties of ryegrass, cocksfoot and timothy. Emp. J. exp. Agric. 27: 291-299.

Gildenhuys, P. J., 1950. Fertility studies in Setaria sphacelata (Schum) Stapf and Hubbard. Sci. Bull. 314, Government Printer, Pretoria.

Hacker, J. B. \& R. J. Jones, 1969. The Setaria sphacelata complex - a review. Trop. Grasslds 3: 13-34.

Langer, R. H. M. \& D. A. Lambert, 1963. The physiological significance of population density in grass seed production. J. Br. Grassld Soc. 18: 177-179.

Ryle, G. J. A., 1966. Physiological aspects of seed yield in grasses. In: F. L. Milthorpe \& J. D. Ivins (Ed.), The growth of cereals and grasses. Butterworths, London.

Sonneveld, A., 1962. Distribution and re-distribution of dry matter in perennial fodder crops. Neth. J. agric. Sci. 10: $427-444$. 